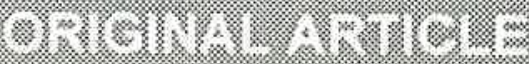

\section{Diagnostic Accuracy of Electrocardiographic Criteria for Left Ventricular Hypertrophy in Thalassemia Syndrome}

\author{
Sudigdo Sastroasmoro, Deddy Ria Saputra, Bambang Madiyono, \\ Ismet N Oesman, Sukman Tulus Putra \\ (Department of Child Health, Medical School, \\ University of Indonesia, Jakarta)
}

\begin{abstract}
We compared the diagnostic accuracy of electrocardiographic (ECG) criteria for left ventricular hypertrophy (LVH) in 119 randomly selected from 400 patients with thalassemia major treated at the Department of Child Health, Medical School, University of Indonesia, Jakarta. Echocardiographically derived left ventricular hypertrophy (EchoLVH), both for body surface area (BSA)-indexed and height-indexed, served as the gold standard. There were 57 girls and 62 boys available, ranging in age from 5 to 27 years. ECG criteria for LVH was detected in 23 out of 119 patients, while echo-LVH was detected in 47 patients if BSA-indexed LVH was used, or 22 patients if height-indexed LVH was used. The sensitivity and specificity of ECG-LVH were 25.5 and $84.7 \%$ respectively if BSAindexed LVH was used as gold standard, or $36.4 \%$ and $84.5 \%$, respectively, when heightindexed echo-LVH was used. It is concluded that ECG criteria for LVH has a low sensitivity and high specificity in detecting increased left ventricular mass in children with thalassemia major. [Paediatr Indones 1995; 35:132-140]
\end{abstract}

\section{Introduction}

Thalassemia is the most frequently found intracorpuscular hemolytic anemia in Indonesia In the Department of Child Health, Medical School, University

Accepted for publication: December 19, 1994. Author's address: Sudigdo Sastroasmoro, MD, Department of Child Health, Medical School, University of Indonesia, Jakarta 10430, Indonesia. Tel (62)(21) 315-5742, Fax 390-7743. of Indonesia, Jakarta, not less than 20 new patients with thalassemia major are diagnosed yearly. ${ }^{1}$ This inherited disease results from incompletely developed beta hemoglobin, resulting in continuing hemolysis. ${ }^{2}$ To maintain metabolism and normal growth, patients with thalassemia major need repeated blood transfusion to keep the hemoglobin level of 10 $\mathrm{g} / \mathrm{d}$ or more. ${ }^{1}$ This leads to the accumulation of iron in the organs (hemoside- 
rosis), which may affect the organ function (hemochromatosis). ${ }^{3}$

Iron deposit in thalassemic patients can occur in the myocardium which might lead to myocardial thickening, conduction disturbances, dysrhythmias, pericarditis, or cardiac failure. ${ }^{47}$ Radiological examination is not considered as a reliable tool to detect cardiac involvement in thalassemic patients, while the role of electrocardiography (ECG) is unclear. There has been no study evaluating the accuracy of ECG criteria for left ventricular hypertrophy (LVH) in patients with thalassemia major. ECG has a low sensitivity and specificity to determine LVH in adult patients with coronary heart disease, but it has a fair sensitivity and specificity in pediatric patients with rheumatic heart disease. ${ }^{3}$ This study aims to determine the sensitivity, specificity, predictive values, and likelihood ratios of ECG in detecting LVH in patients with thalassemia using echocardiography as the gold standard.

\section{Methods}

This diagnostic study was conducted at the Department of Child Health, Medical School, University of Indonesia - Cipto Mangunkusumo Hospital, Jakarta, from August 1991 through September 1993. Study subjects were recruited from thalassemic patients attending the Department of Child Health. There were overall 400 patients with thalassemia major available.

We included patients of both sexes, those aged 5 years or more, and who had been diagnosed as having thalassemia major by means of history, physical findings, and hemoglobin analysis. Excluded were patients who had cardiac disease caused by other than thalassemia, and who refused to participate in the study.

Subjects were selected by random sampling. The sample size was calculated according to the formula for proportion. ${ }^{9}$ One hundred and fifteen patients were considered sufficient.

In all patients the following variables were determined: age, sex, body height and weight. Body surface area was calculated by using standard formula ${ }^{10}$

ECG tracing was obtained by using "Manual Cardiosuny 501 D electrocardiography" by an experienced nurse, with the patients in a supine position. Standard 6 extremity and chest leads were taken from each patients; in addition $a V_{3 R}$ or $V_{4 R}$ was obtained. Standard M-mode echocardiography was performed using Toshiba Sonolayer SSH 65 A with 3.75 or $2.5 \mathrm{MHz}$ transducer. $\mathrm{Pa}$ tients were examined in a left lateral decubitus position. The speed of M-mode tracing was set at 25 to $50 \mathrm{~mm}$ per second. At least 3 prints were made. Left ventricular mass was calculated according to Devereux's formula: ${ }^{11}$

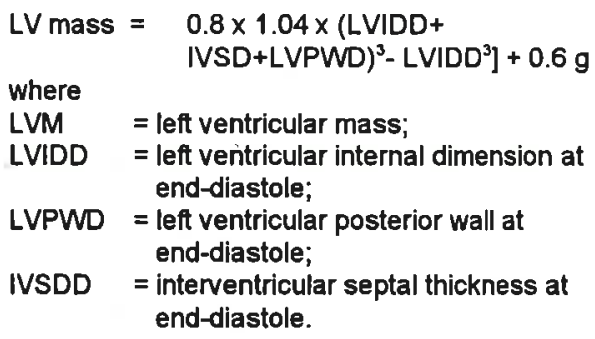

All M-mode measurements were made according to leading edge to leading edge 
convention ${ }^{12}$ The echocardiograms were reviewed by one of the authors (SS) who was unaware of the result of clinical and electrocardiographic results of the patient. Each value was obtained by averaging 3 recordings.

The nutritional status of patients aged 5 years was determined using weight for age standard (NCHS), for those aged 617 years was determined by Jumadias anthropometric standard, and for those aged 18 years or more was determined by using "Society of Actuaries" 1959.13 The classification of nutritional status followed the Workshop on Nutrition Department of Health (1975) and Center for Research and Development of Nutrition (1978). ${ }^{14}$

Electrocardiographically determined left ventricular hypertrophy (ECG-LVH)

Diagnosis of ECG-LVH was established when one or more criteria of Liebman and $Z_{\text {iegler }}{ }^{15}$ was fulfilled. The criteria were: (a) $R$ wave in $V_{6}>21 \mathrm{~mm}$ (b) $S$ wave in $V_{1}>25 \mathrm{~mm}$, (c) $R / S$ ratio in $V_{3}$ or $V_{1}<0,1$; (d). q wave in $V_{5}$ or $V_{6}>3 \mathrm{~mm}$.

\section{Echocardiographically-determined left} ventricular hypertrophy (Echo-LVH)

The diagnosis of Echo-LVH was established by echocardiography when the left ventricular mass, indexed for body height and body surface area, respectively, was more than 99,8 gram/m or $103 \mathrm{gram} / \mathrm{m}^{2}$ in boys, or more than 81,0 gram $/ \mathrm{m}$ or 84,2 gram/ $\mathrm{m}^{2}$ in girls. ${ }^{16,17}$

\section{Statistical analysis}

The results of ECG-LVH were compared to Echo-LVH which served as the gold standard. The following values were calculated: sensitivity, specificity, positive and negative predictive values, and positive and negative likelihood ratios. For each value, $95 \%$ confidence intervals $(95 \% \mathrm{Cl})$ were calculated using standard formulas. ${ }^{18,19}$

Chi-squared test for trend was used to compare changes in left ventricula hypertrophy with increasing age. All statistical tests were considered significan when the $p$ value was $<0.05$. The statistical analyses were done manually with the help of True-Epistat statistical program.

\section{Results}

From August 1991 through September 1993, there were 127 patients fulfilling study criteria. Eight patients were excluded from the study due to incomplete data Therefore, 119 patients were available for analysis.

\section{Age and sex distribution}

There were 119 patients aged 5-27 years studied, consisted of 57 females and 62 males. The sex and age group distribution is depicted in Table 1.

Table 1. Age and sex distribution of study subjects

\begin{tabular}{rrrr}
\hline $\begin{array}{c}\text { Age } \\
(\mathrm{yr})\end{array}$ & Girls & Boys & Total \\
\hline $5-$ & 19 & 25 & 44 \\
$10-$ & 24 & 28 & 52 \\
$\geq 15$ & 14 & 9 & 23 \\
\hline Total & 57 & 62 & 119 \\
\hline
\end{tabular}

\section{Nutritional status}

The nutritional status of the 119 patients is depicted in Table 2. It appears that three-fifth of all patients were wellnourished, while one-third were undernourished. Only few patients were overweight or malnourished.

Table 2. The distribution of nutritional status of 119 patients with thalassemia major

\begin{tabular}{lrc}
\hline Nutritional status & No & Percentage \\
\hline Overweight & 2 & $1.7 \%$ \\
Well-nourished & 71 & $60.0 \%$ \\
Undernourished & 36 & $30.3 \%$ \\
Severely & 6 & $5.0 \%$ \\
malnourished & & \\
\hline Total & 119 & $100.0 \%$ \\
\hline
\end{tabular}

\section{Electrocardiography}

LVH was diagnosed by ECG in 23 patients, consisted of 8 girls and 15 boys. When stratified according to age group, it appears that in the age group of 5-10 years there were $11,4 \%$ patients with LVH, while in the age group of 10-15 years and more than 15 years the percentages were $17,3 \%$ and $39,1 \%$ respectively. The trend was that the older the age group, the higher was the percentage of ECG-LVH. Statistical analysis showed that this trend was more clearly seen in boys than in girls. See Table 3.

\section{Echocardiography}

On M-mode echocardiography at the level of left ventricle, the mean left ventricular internal dimension at diastole.
Table 3. Proportion of ECG-LVH according to age and sex

\begin{tabular}{ccrc}
\hline Age $(\mathrm{yr})$ & Girls & Boys & Total $(\%)$ \\
\hline $5-$ & $1 / 19$ & $4 / 25$ & $5 / 44(11.4 \%)$ \\
$10-$ & $2 / 19$ & $7 / 28$ & $9 / 52(17,3 \%)$ \\
$>15$ & $4 / 19$ & $5 / 9$ & $9 / 23(39,1 \%)$ \\
\hline Total & $7 / 19$ & $16 / 62$ & $23 / 119(19,3 \%)$ \\
\hline
\end{tabular}

Chi-square for trend $=5.122 ; d f=1 ; p=0.024$

was 3.8 (SD 0.60) $\mathrm{cm}$, the mean left ventricular posterior wall thickness at enddiastole was 0.74 (SD 0.2) $\mathrm{cm}$, and the mean interventricular septum thickness at end-diastole was 0.80 (SD 0.26) cm. In $22(18 \%)$ patients the left ventricular internal dimension was the same as, or more than, that of $95 \%$ normal value for age. In thirty-seven (31\%) of patients the left ventricular posterior wall thickness was the same as, or more than, 95\% percentile of normal value for age.

Body surface area (BSA)-indexed LVH was found in 47 patients, comprising 26 females and 21 males. In the age group of 5-10 years, LVH was found in 29.5\%, while in 10-15 years and 15 years or more age group the percentages were $34.6 \%$ and $69.6 \%$, respectively. It is also shown that the percentage of BSAindexed LVH increased with increasing age group. However, unlike ECG-LVH, chi-square for trend analysis did not show any significant difference between boys and girls. See Table 4 .

Table 5 shows that height-indexed Echo-LVH was found in only $22(18.5 \%$ of the 199 patients. The percentage of height-indexed Echo-LVH was also increased with increasing age group in 
both sexes, but the difference in trend was not statistically significant between boys and girls.

Table 4. Proportion of Echo-LVH (BSA-indexed) according to age and sex

\begin{tabular}{crrc}
\hline Age $(\mathrm{yr})$ & Girls & Boys & Total $(\%)$ \\
\hline $5-$ & $7 / 19$ & $6 / 25$ & $13 / 44(29.5 \%)$ \\
$10-$ & $8 / 24$ & $10 / 28$ & $18 / 52(34.6 \%)$ \\
$>15$ & $11 / 14$ & $5 / 9$ & $16 / 23(69.5 \%)$ \\
\hline Total & $26 / 57$ & $21 / 42$ & $47 / 119(39.5 \%)$ \\
\hline
\end{tabular}

Chi-square for trend ; $x^{2}=0.916 ; d f=1 ; p=0.339$

Table 5. Proportion of body height-indexed EchoLVH according to age and sex

\begin{tabular}{rrrr}
\hline $\begin{array}{c}\text { Age } \\
\text { (year) }\end{array}$ & Girls & Boys & \multicolumn{1}{c}{ Total } \\
\hline $5-$ & $3 / 19$ & $0 / 25$ & $3 / 44(6,8 \%)$ \\
$10-$ & $4 / 24$ & $5 / 28$ & $9 / 52(17,3 \%)$ \\
$>15$ & $7 / 14$ & $3 / 9$ & $10 / 23(43,5 \%)$ \\
\hline Total & $14 / 57$ & $8 / 62$ & $22 / 119(18,5 \%)$ \\
\hline
\end{tabular}

Chi-square for trend; $x^{2}=0.622 ; d f=1 ; p=0.430$

\section{Sensitivity and specificity of ECG-LVH}

ECG LVH was found in 23 (19.3\%) patients, and on echocardiography it was 47 patients $(39.4 \%)$ if $\mathrm{BSA}$ index was used, or 22 patients $(18.5 \%)$ if body height index was used. The sensitivity and specificity of ECG in detecting LVH was then $25.5 \%$ and $84.7 \%$ in $\mathrm{BSA}$ indexed echo was used as gold standard, or $36.6 \%$ and $84.5 \%$ if body height indexed echo was used as gold standard. Tables 6 and 7 describe the complete features of sensitivity, specificity, predic- Table 6. Diagnostic accuracy of ECG-LVH in patients with thalassemia major using BSA-indexed Echotive values, and likelihood ratios of ECG- LVH as the gold standard

LVH using BSA-indexed or height- indexed Echo-LVH, respectively.

\section{Discussion}

Echocardiography has proven to be a reliable non-invasive method to evaluate cardiac chamber and wall dimensions, ventricular contractility, and other parameters. ${ }^{20}$ Using specific formula, left ventricular mass can also be determined by M-mode echocardiography, which is well correlated with autopsy. ${ }^{11}$

To reduce the possibility of errors due to chance and bias in this cross sectional diagnostic test, several attempts have been made. These included random selection of the patients, a strict operational definitions, and the blinding of the reviewer when analyzing ECG or echocardiography.

\section{Patient's characteristics}

The boy to girl ratio of the 119 patients in this study was approximately $1.1: 1$. This was not very different to that reported by Wahidiyat $^{1}(3: 2)$ or by Dewi ${ }^{21}$ and Sinulingga ${ }^{22}(4: 3)$.

\section{Echocardiography}

Repeated blood transfusion in thalassemic patients results in the increase of transversal dimension of left ventricular chamber, increase in thickening of left ventricular wall, and increase in left ventricular mass. ${ }^{20}$ These phenomena is not only found in older patients, but also in

\begin{tabular}{cccc}
\hline \multicolumn{4}{c}{ Echo-LVH } \\
\hline & Yes & No & Total \\
\hline Yes & 12 & 11 & 23
\end{tabular}

ECG-LVH

\begin{tabular}{cccc} 
No & 35 & 61 & 96 \\
\hline Total & 47 & 72 & 119 \\
\hline
\end{tabular}

Sensitivity Specificity Accuracy Positive predictive value $=12 / 23=52.2 \%(95 \% \mathrm{Cl}=36.6 \% ; 67.8 \%)$ Negative predictive value $=61 / 96=63.5 \%(95 \% \mathrm{Cl}=55.3 \% \cdot 71.7 \%)$ Positive likelihood ratio $=1.67(95 \% \mathrm{Cl}=1.13 ; 4.88)$

Negative likelihood ratio $=0.88(95 \% \mathrm{Cl}=0.64 ; 0.95)$
Table 7. Diagnostic accuracy of ECG-LVH in patients with thalassemia major using body height-indexed Echo-LVH as the gold standard

\begin{tabular}{cccc}
\hline \multicolumn{4}{c}{ Echo-LVH } \\
\hline & Yes & No & Total \\
\hline Yes & 8 & 15 & 23
\end{tabular}

ECG-LVH

\begin{tabular}{cccc} 
No & 14 & 82 & 96 \\
\hline Total & 22 & 97 & 119 \\
\hline
\end{tabular}

Sensitivity

Specificity

Accuracy

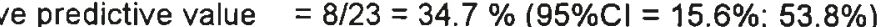

Negative predictive value $=82 / 96=85.4 \%(95 \% \mathrm{Cl}=78.4 ; 92.4 \%)$

Positive likelihood ratio $=2.35(95 \% \mathrm{Cl}=0.81 ; 3.44)$

Negative likelihood ratio $=0.78(95 \% \mathrm{Cl}=0.63 ; 1.22)$ 
younger ones. In this study there was an increase of transversal dimension, thickening of left ventricular wall, and increase of left ventricular mass with increasing age. These were in accord with those reported by Henry et al. ${ }^{20}$ We did not examine the correlation between those cardiac measurements and the amount of blood transfusion received.

\section{Accuracy of ECG-LVH}

The use of electrocardiography in detecting $\mathrm{LVH}$ in cardiac patiens has been questioned by many..$^{23}$ In most adult patients, the sensitivity of ECG in detecting LVH is very low, when compared with that obtained by echocardiography or autopsy. In this study the sensitivity of ECG in detecting LVH was low (25.5\%) but its specificity was high $(84.7 \%)$. This result was different with those reported by Sastroasmoro ${ }^{8}$ who found good sensitivity $(71.4 \%)$ and specificity $(73.8 \%)$.

The corresponding predictive values and likelihood ratios of ECG-LVH (Tables 6 and 7 followed the sensitivity and specificity of ECG-LVH. The low sensitivity and high specificity in this study corresponded with low to moderate predictive values and high negative predictive values, with high positive likelihood ratios and low negative predictive values.

In contrast to absence of sex difference, the sensitivity of ECG to detect LVH showed significant difference with increasing age. ECG was more sensitive to detect LVH in patients more than 15 years of age than on those below 15 years. This was an accord with other report, ${ }^{24}$ which might be cause by paradoxical phenomena associated with the increased prevalence of LVH in older age as a result of repeated blood transfusion. According to Devereux ${ }^{11}$ the best method in measuring LV mass by means of echocardiography is the Penn's method. This method excludes the endocardium in the myocardial thickness measurement but includes it in the left ventricular dimension. In this study we did not use this method because of the difficulty in determining endocardial thickness, especially in small children. In contrast to in adults, there is no standard values for $L V$ mass measured by echocardiography.

In determining $L V$ mass by means of echocardiography BSA-indexed LVH is more often used than height-indexed LVH. However, some investigators reported that the use of height-indexed is more reliable when compared with BSAindexed LV mass. In this study we used BSA-indexed LVH due to the many patients who were undernourished. In well-nourished children, BSA/height ratio usually gives larger value than in adults. The presence of undernutrition, as shown by low body weight and normal height will result in low BSA. This will result in lower body height-indexed LV mass when compared with BSA indexed LV mass.

Our results show that the role of ECG in detecting LVH in patients with thalassemia major was very low, especially in patients aged $5-10$ years (Table 3 ). This makes echocardiography has the important place in the overall management of patients with thalassemia major, especially in its relation with cardiac involvement.

It must be borne in mind that in the management of thalassemia the use of desferrioxamine, an agent that binds the iron, has the most important role in the prevention of iron deposit in the body organs, especially in the myocardium. In addition, splenectomy has to be seriously considered if frequent blood transfusion is needed (>180 ml/KgBW/year). Spenectomy will suppress the erythropoeisis and reduce the need for transfusion resulting in reduction of iron deposit.

In conclusion, our data indicate the following: (1) ECG can detect LVH in $19.3 \%$ of thalassemia patents aged 5 years or more; (2) BSA-indexed echo$\mathrm{LVH}$ is more sensitive to detect left ventricular mass increase than heightindexed echo-LVH; (3) ECG has low sensitivity but high specificity in detecting LVH in thalassemia patients; (4) The sensitivity of ECG criteria for LVH is not different according to sex, but tends to increase with increasing age.

\section{References}

1. Wahidiyat I. Penelitian thalassemia di Jakarta. Tesis. Jakarta: Intermega, 1979.

2. Weatherall DJ. The thalassemia. Hematology; 3rd ed. New York: Mc Graw-Hill 1983; 493-517.

3. Keberle $H$. The biochemistry of desferrioxamine and its relation to iron metabolism. Ann N Y Acad Sci 1964; 119:758 68.

4. Kaye SB, Owen M. Cardiac arrhythmias in thalassemia major: Evaluation of che lation treatment using ambulatory monitoring. Br Med J 1977; 342.

5. Koren A, Garty L. Right ventricular car diac dysfunction in beta thalassemia major. Am J Dis Child 1976; 141:93-6.

6. Leon MB, Borer JS. Detection of early cardiac dysfunction in patient with thalassemia and chronic iron overload. N Engl J Med 1978; 301:1143-8.

7. Engle MA, Erlandson M, Smith $\mathrm{CH}$. Late cardiac complications of chronic, severe, refractory anemia with hemochromatosis. Circulation 1964; 30:698-704

8. Sastroasmoro S, Madiyono B, Oesman IN. Sensitivity and specificity of electroIN. Sensitivity and specificity of electrocardiographic criteria for left ventricular hypertrophy in children with rheumatic heart disease. Paediatr Indones 1991

9. Browner WS, Newman TB, Cummings SR. Designing a new study: III. Diagnostic test. In: Hulley SB, Cumming SR, eds. Designing clinical research. Baltimore: Williams \& Wilkins, 1988; 87-97.

10. Ganong WP. Review of medical physiology; 6th ed. California: Lange Medica Publ., 1973: 200.

1-1. Devereux RB, Alonso DR, Lutas EM, et al. Echocardiographic assessment of left ventricular hypertrophy: Comparison of necropsy findings. Am J Cardiol 1986; 57:450-8.

12. Sahn DJ, Demaria A, Kisslo J, Weyman A. The Committee on M-mode Standardization of the American Society of Echocardiography. Recommendations regarding quantitation in $\mathrm{M}$ mode echocardiography : result of a survey of echocardiographic measurements. Circulation 1978; 58:1072-81.

13. Tarwotjo I, Soekirman. Status gizi anak. Gizi Indones 1987; 12:6-14.

14. Panitia asuhan nutrisi. Bahan-bahan pelatihan. In: Simposium dan Pelatihan Gizi Klinik. Jakarta 1993.

15. Goldschlager N, Goldman MJ. Principles of clinical electrocardiography; 13th ed San Francisco: Lange, 1989; 58-72.

16. Silverman NH. Pediatric echocardiography. Baltimore: Williams \& Wilkins, 1993; 35-108.

17. Daniels SR, Meyer RA, Liang Y. Echocardiographically determined left ventri- 
cular mass index in normal children, adolescents, and young adults. J Am Coll Cardiol 1988; 12:703-8.

18. Dawson-Saunders B, Trapp RG. Estimating and comparing proportions. In: Dawson-Saunders B, Trapp RG, ed. Basic and clinical biostatistics. East Norwalk: Appleton \& Lange, $1990 ; 142-60$.

19. Morris JA, Gardner MJ. Calculating confidence intervals for relative risks, odds ratios, and standardized ratios and rates. In: Gardner MJ, Altman, ed. Statistics with confidence. London: $\mathrm{Br}$ Med J, 1989; 50-2.

20. Henry. WL, Nienhuis AW, Wiener M, Miller DR, Canale VC, Piomelli S. Echocardiographic abnormalities in patients with transfusion dependent anemia and secondary myocardial iron deposition. Am J Med 1978; 64:547-55.
21. Dewi LP. Profil pertumbuhan jasmani pada pasien talasemia mayor. Tesis. Jakarta: Bagian Ilmu Kesehatan Anak FKUI, 1992.

22. Sinulingga S, Loebis IF, Sutjipto A. The pattern of thalassemia in children at the Department of Child Health, School of Medicine University of North Sumatera/ Dr Pirngadi Hospital, Medan. Paediatr Indones 1991; 31:261-7.

23. Devereux RB. Is the electrocardiogram still useful for detection of left ventricular hypertrophy? Circulation 1990; 81: 1144-6.

24. Levy D, Labib SB, Anderson KM, Christiansen JC, Kannel WB, Castelli WP. Determinants of sensitivity and specifity of electrocardiographic criteria for left ventricular hypertrophy. Circulation 1990; 81:815-20. 